\title{
Enhancement of the interface of friction welded steel-aluminium joints
}

\author{
Bernd-Arno Behrens ${ }^{1} \cdot$ Deniz Duran ${ }^{1} \cdot \operatorname{Tim}_{\text {Matthias }}{ }^{2} \cdot$ Ingo Ross $^{1}$ (i)
}

Received: 31 July 2020 / Accepted: 26 October 2020 / Published online: 22 November 2020

(c) The Author(s) 2020

\begin{abstract}
Lightweight multi-material components are of great importance for the transport industry. Not only the component's weight can be decreased, but also its local properties can be adapted to different loading profiles. Tailored Forming is a novel concept for producing multi-material components. By using a joining process, the creation of a bond between different materials takes place in the first step of the process chain. In the subsequent steps, multi-material workpieces are processed in their joined state while maintaining or improving the joint strength. This study focuses on steel-aluminium joints, which were created by friction welding and further processed by induction heating and impact extrusion. A counter pressure superposition mechanism was implemented in the extrusion tooling to control the stress state during plastic deformation. Flow behaviours of steel and aluminium are largely different at a given temperature, which necessitates a near step-function temperature distribution in the hybrid billet to obtain matching flow stresses. An inductive heating strategy was developed which led to a temperature gradient in the billets before extrusion. Extruded billets were analysed by destructive testing methods and metallography. The bond could be maintained after extrusion when counter pressure superposition was used; but no improvement could be obtained. Without counter force superposition, however, cracks were observed in the joining interface and the joint strength decreased. This paper discusses the aforementioned findings in the current process design and makes suggestions on how the involved processes should be reconfigured to improve the joint strength.
\end{abstract}

Keywords Tailored Forming $\cdot$ Multi-Material Components $\cdot$ Friction Welding $\cdot$ Impact Extrusion

\section{Introduction}

Driven by rising energy and material costs as well as growing environmental awareness, energy and resource efficiency are increasingly becoming the focus of research and industry. Within the automotive industry, efficient lightweight construction enables weight and fuel consumption to be reduced. New materials are constantly being developed to achieve weight savings. Nevertheless, mono-material

Ingo Ross

ross@ifum.uni-hannover.de

Bernd-Arno Behrens

behrens@ifum.uni-hannover.de

Deniz Duran

duran@ifum.uni-hannover.de

Tim Matthias

tmatthias@ifum.uni-hannover.de

1 Institute of Forming Technologies an Machines, Leibniz University Hannover, Hanover, Germany components are reaching their limits. Hybrid concepts can be used to further advance lightweight construction. In addition, hybrid components allow for adapted material properties that are appropriate for the local application purpose.

Hybrid components are usually joined in a near-net-shape condition from two or more different materials. This means that the joining process is located at the end of the process chain. The Tailored Forming approach, developed in Collaborative Research Centre (CRC 1153), consists of a preceding joining step to combine the different materials to a hybrid blank and a subsequent further processing. The joining zone properties can be adapted and improved during forming, machining and heat treatment. The simultaneous processing of different materials results in process-specific challenges that must be solved, in order to achieve good and reproducible results.

Figure 1 shows the process chain for the production of a hybrid shaft. First of all, the different materials are joined by laser beam welding or friction welding. Subsequently the materials are heated inductively and formed by impact 


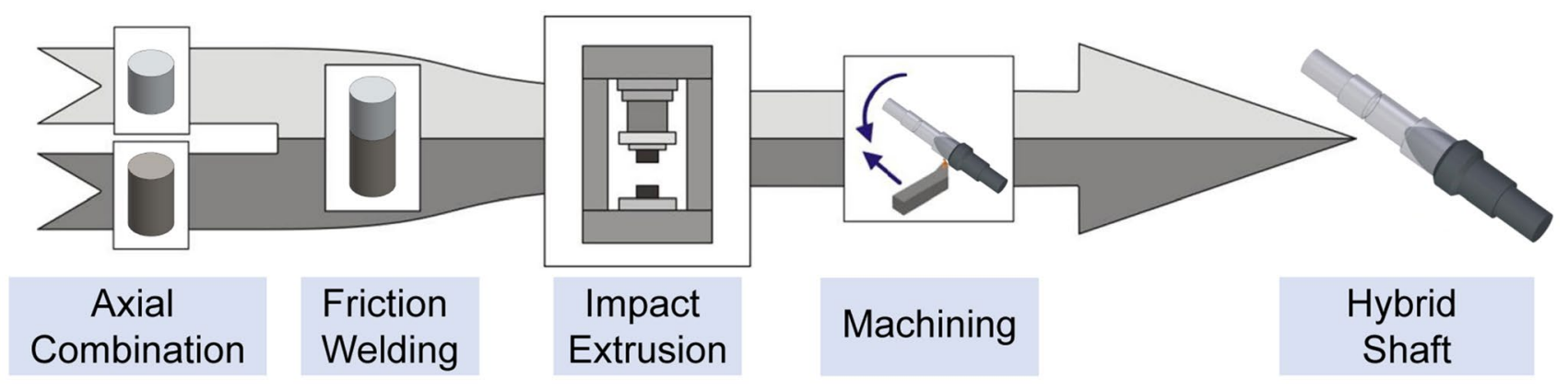

Fig. 1 Process chain of the CRC 1153 for the manufacturing of a hybrid shaft

extrusion. Following the heat treatment, the components are machined to their final geometry.

\section{State of the art}

\subsection{Production of multi-material components}

Hybrid semi-finished products made of different materials or sheet thicknesses have been well established in sheet metal forming [1, 2]. In contrast, there are only a limited number of approaches in this direction in bulk metal forming.

Domblesky et al. conducted a fundamental investigation of the process combination of friction welding and forming [3]. The joints were made of steel, aluminium and copper. The friction- welded joints were subjected to upsetting or flank pressing. They showed that semi-finished products made of either similar or dissimilar materials can be processed by using this innovative process combination. In the Collaborative Research Centre CRC 692 of the Chemnitz Technical University, compound extrusion tests were carried out to obtain a bond between aluminium and magnesium alloys [4-6]. It could be shown that the resulting metallurgical joints do not fail even under high loads. Foydl et al. [7] developed a compound extrusion process to fabricate steel-reinforced aluminium profiles. Sections were cut from the extruded profiles and used as billets in a die forging process in order to produce hybrid connecting rods. It was shown that the steel-aluminium interface remained intact after the forging process [8]. Wang et al. carried out a combined numerical and experimental investigation on the forging of steel-steel workpieces [9]. Cylinders made of mild steel were deposited with stainless steel. The hybrid billets were then hot forged at different temperatures.

Another process concept for the production of hybrid components is the compound forging. In this concept, a joining process is not utilised to create a joint between the materials. Instead, the joint is achieved during the forging process. In compound forging, a dimensionally accurate heating strategy is crucial, especially in the case of dissimilar material pairs. During the forming process, brittle intermetallic phases can occur in the interface for certain material combinations, e.g. steel-aluminium [10]. Diverse hybrid components in the automotive industry, such as connecting rods, wheel hubs and wishbones, are manufactured by Leiber Group GmbH \& Co. KG, where the material joint is produced in particular by frictional and positive locking [11]. In most cases, however, such joining processes are very demanding with regards to the process control and safety requirements. The generation of a uniform and continuous joining zone with reproducible properties is challenging. An important aspect to address this is to match material-specific properties of the materials for a successful implementation of the deformation processing step.

\subsection{Friction welding}

Friction welding is a type of press welding process. The materials are joined by means of plastic deformation. The heat required for the formation of welded joint is generated by the friction arising as a result of the relative movement of one workpiece against the firmly fixed joining partner as well as due to the pressing force acting on the workpieces. Thus, this process is of particular advantage not only for the application of similar materials but also for the welding of material combinations, which cannot be joined by the application of other welding processes. Due to the temperatures just below the liquidus temperature, the resulting recrystallization, the high compressive stresses as well as the resulting intensive material deformation, a very fine-grained microstructure with particularly good static and dynamic mechanical properties can be achieved. The relatively shorter heating time, as compared to the fusion welding, leads to a very small expansion of the heat affected zone and limits the thermally induced, undesirable structural changes 
of the base material only to a narrow area around the joining zone. In addition, the simple type of process control due to the few welding parameters, which are also precisely adjustable, leads to a higher and reliably reproducible product quality $[12,13]$. Due to the possibility of combining different materials, this process is of particular interest for a resource efficient use of the materials. The use of friction welding not only saves material, time and energy, but also makes it possible to use expensive materials specifically at the component locations experiencing higher stresses.

\section{Materials and methods}

\subsection{Friction welding}

The first step is the manufacturing of hybrid forging billets by friction welding $20 \mathrm{MnCr} 5$ (DIN 1.7147) steel with EN AW-6082 (DIN 3.2315) aluminium alloy. For preparation of the initial billets for the friction welding, their end faces were face-turned and then an alcohol based cleansing material is applied to the welding surfaces. Central welding parameters are given in the Table 1. Aluminium's flow stress is generally much lower than steel's flow stress. Therefore, steel is not subjected to plastic deformation during the welding process, whilst aluminium is displaced to the welding flash from the rubbing zone. Keeping the rubbing time

Table 1 Process parameters for friction welding of steel-aluminium billets

\begin{tabular}{lllll}
\hline $\begin{array}{l}\text { Billet diam- } \\
\text { eter }\end{array}$ & $\begin{array}{l}\text { Axial short- } \\
\text { ening }\end{array}$ & $\begin{array}{l}\text { Rubbing } \\
\text { pressure }\end{array}$ & $\begin{array}{l}\text { Forging } \\
\text { time }\end{array}$ & $\begin{array}{l}\text { Forging } \\
\text { pressure }\end{array}$ \\
\hline $40 \mathrm{~mm}$ & $3.5 \mathrm{~mm}$ & $130 \mathrm{MPa}$ & $4 \mathrm{~s}$ & $150 \mathrm{MPa}$ \\
\hline
\end{tabular}

excessively long can lead to an unnecessary shortening. For that reason, a short rubbing time is employed. Another advantage of short rubbing phase is that the average joining zone temperature can be kept relatively low and the growth of brittle intermetallics can be prevented. The billet manufacturing is concluded by trimming the welding flash around the joining zone and then cutting off to the required billet size.

\subsection{Impact extrusion}

Although the forward rod extrusion is essentially a compressive stress dominated forming process, tensile stresses also develop in the plastic deformation zone. During deformation, the parts centre is dragged in the reverse direction of material movement as a result of large displacements at the outer zone. Thus, the stress state can change from compression to tension. This is a critical situation in terms of bonding of the two materials constituting the forging billet. Tensile stresses in the joining zone can lead to a partial separation of steel and aluminium and eventually have a negative influence on the resulting bond properties. In order to control the stress state in the joining zone during the deformation process, a forming tool with a counter pressure superposition system was used in the extrusion experiments.

A sectional view of the tool for forward rod extrusion is shown in Fig. 2. A double reinforced extrusion die is used in the forming experiments. It is consisted of a high-speed steel core (DIN 1.3343, 60-62 HRC) and two shrink rings (DIN 1.2344, 46-48 HRC). Below the extrusion die, the system for counter pressure superposition is located. Its elements are a transverse beam, two identical gas springs and a counter punch. The gas springs hold the transverse beam at both ends. The downward movement of the counter punch is restrained by a conical surface in the centre. During forming,
Fig. 2 Sectional view of the impact extrusion tooling [14]

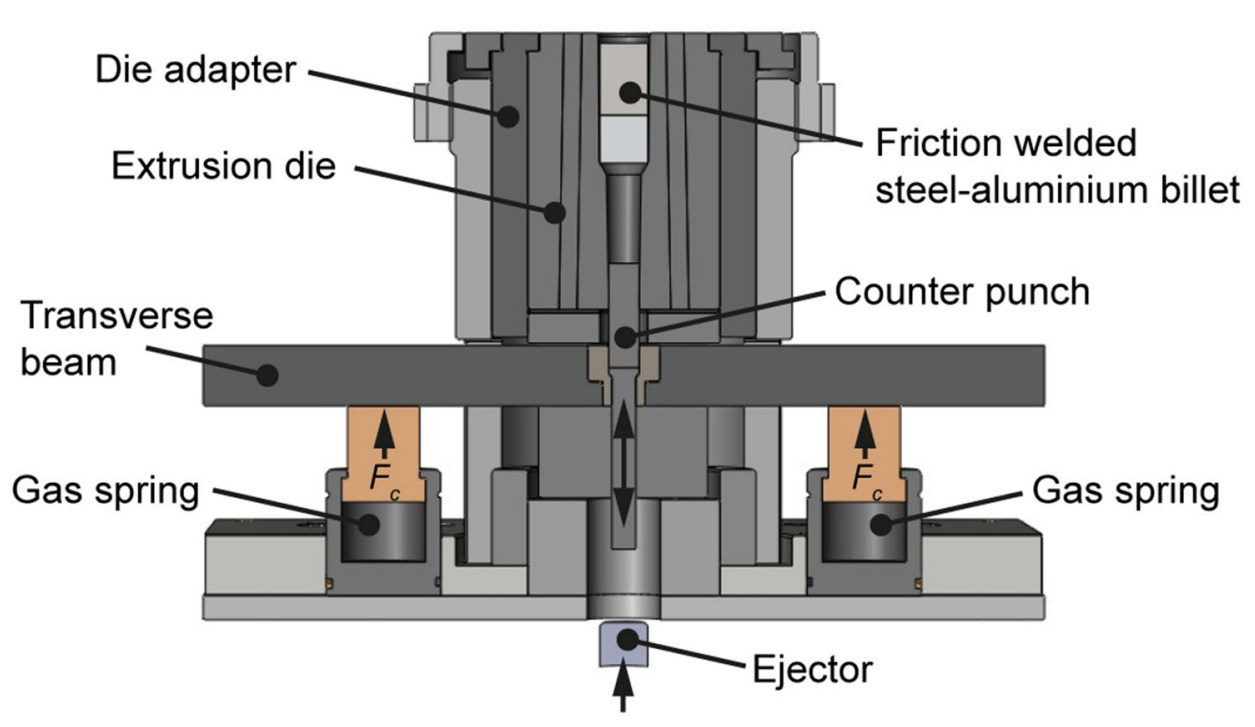


the tip of the extrudate makes contact with the counter punch and forces it to move downwards. The displacements are transmitted on the gas springs whose resistance to the movement superimposes a counter pressure on the workpiece. Once the initial spring force is overcome, the system moves in the direction of press movement. With increasing stroke, the magnitude of the counter pressure increases according to the spring stiffness. The initial spring force and spring stiffness can be adjusted by the filling pressure. In the experiments, the initial force of the system (the total of two gas springs) was $85 \mathrm{kN}$ and the maximum force that was achieved at the end of the stroke was $135 \mathrm{kN}$. This corresponds to an average superimposed pressure of $200 \mathrm{MPa}$ in the workpiece. Before deformation, hybrid workpieces are coated with graphite and a graphite containing oil was applied on the die's active surface. After deformation, the formed workpiece is released immediately through the force of gas springs and kicked out of the die by using the ejector of the press.

\subsection{Induction heating}

Induction heating was preferred as the heating method for hybrid forging billets. A generator with $40 \mathrm{~kW}$ maximum power output was used which can be operated in a frequency range between 5 and $30 \mathrm{kHz}$. Forming of steelaluminium billets is challenging, because they exhibit different flow stresses at a given temperature. An analysis of the flow curves revealed that $900{ }^{\circ} \mathrm{C}$ in steel matches $20^{\circ} \mathrm{C}$ in aluminium. Therefore, a near step-function temperature distribution should be generated in the hybrid billet in order to obtain a favourable forming behaviour. The hybrid billet is translated in the inductor with the joining zone positioned at the top turn of the coil (aluminium outside the inductor). A copper cylinder is placed below the steel to prevent overheating of steel ends due to electromagnetic end-effect. $20 \mathrm{~s}$ of heating at a power output of $65 \%$ led to significant axial temperature gradients in the hybrid billet. Radial gradients even out during the transport of the billet into the forming die. The development of this heating strategy is based on detailed numerical modelling and experimental validation whose details can be seen in [14].

\section{Analysis of the resulting joint properties}

In order to analyse the joining zone, the extruded workpieces were cut longitudinally by using an abrasive cutting machine. A relatively flat joining zone was observed, see Fig. 3a. The axial temperature gradient in the joining zone was not steep enough to yield a match between the flow stresses of steel and aluminium. Therefore, plastic deformation of the steel is not significant in the joining zone and a penetration of the materials into each other through plastic deformation is only marginal. The counter pressure superposition did not affect the geometry of the joining zone.

Metallographic specimens were prepared from sectioned workpieces. Steel and aluminium were etched by two different etching solutions based on nital and hydrofluoric acid, respectively. Micrographs were taken over the joining zone by using a light microscope. Intermetallics could not be observed under the light microscope, neither in the friction welded specimen nor in the extruded specimens. In general, a good material bond was observed throughout the joining zone of the specimen extruded with counter pressure superposition (Fig. 3c). On the other hand, central cracks were noticed in the specimen extruded without counter pressure superposition (Fig. 3b). These are only apparent in the aluminium and propagate nearly $30 \mu \mathrm{m}$. Tensile stresses occurring in the joining zone during the extrusion process should account for the cracks observed. By superimposing counter

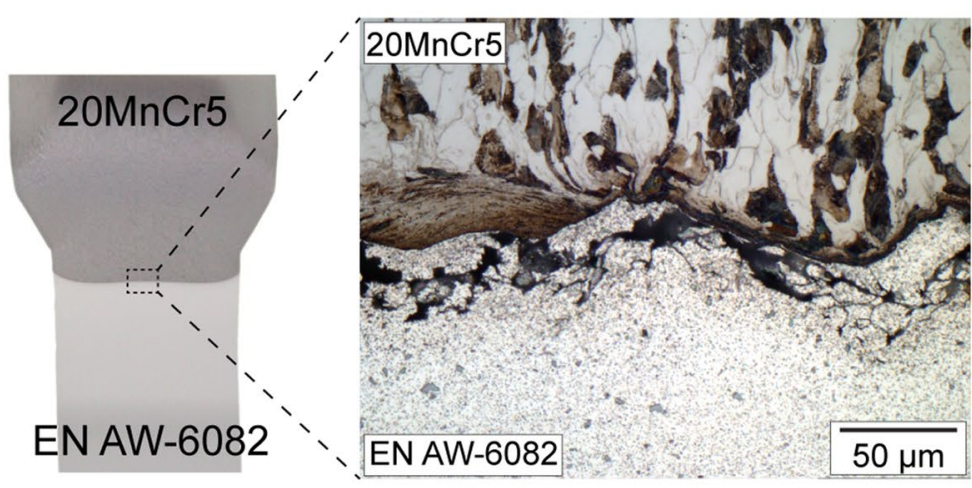

(a) (b)

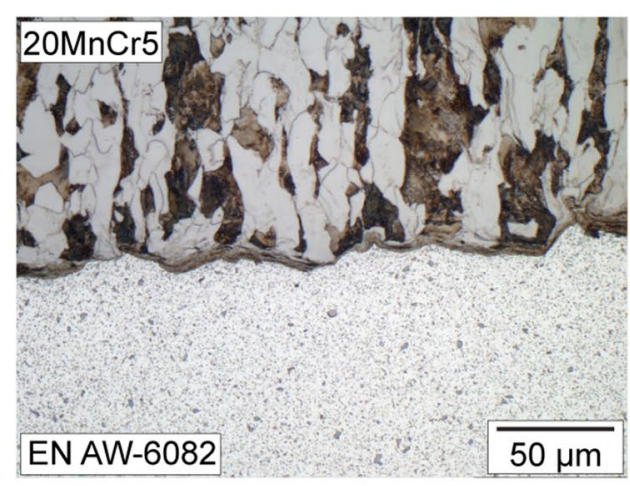

(c)

Fig. 3 Steel-aluminium joining zone after extrusion (a) and the central micrographs: (b) without counter pressure superposition; (c) with counter pressure superposition [15] 
pressure, however, the stress state could be controlled which led to the elimination of cracks.

The resulting bond strength was investigated by tension tests. For each case, three test specimens were extracted from extruded steel-aluminium workpieces. Because of the forging heat, aluminium's precipitation-hardened microstructure is deteriorated after forming. In order for aluminium to regain its favourable microstructural properties, the test specimens were subjected to precipitation hardening. Steel was left untreated. After heat treatment, tension tests were carried out whose results are shown in Fig. 4. In all specimens, fracture occurred in the joining zone. A high deviation in the tensile strength was found, especially in the conventionally extruded specimens. The propagation of damage appears to be different in the investigated specimens. More tests should be carried out to better understand this phenomenon. By using the counter pressure superposition, tensile strength could be improved by $30 \%$. The test results were also found to be consistent with the metallography findings. The average strength
This can be regulated by an adapted process control during the forming process. Further extrusion processes are possible, which introduce different load profiles into the joining zone. In addition, improved thermal process control can have a positive effect on the joining zone. The focus of this is to increase temperature gradients. Another possibility to improve the joining zone geometry is to adjust it already before forming. Furthermore, the material connection, which is created between the materials as a result of the friction welding process, can also be supplemented by an additional force and form closure on the basis of the joining zone design. The detailed improvement suggestions are discussed below.

\subsection{Friction welding}

In order to adjust the formation of the joining zone in hybrid semi-finished products before forming, the blanks must be machined before the friction welding process. The steel geometry does not undergo any macroscopic changes during

Fig. 4 Determination of the tensile strengths of steel-aluminium joints

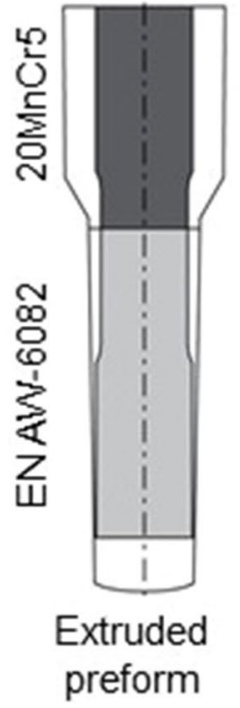

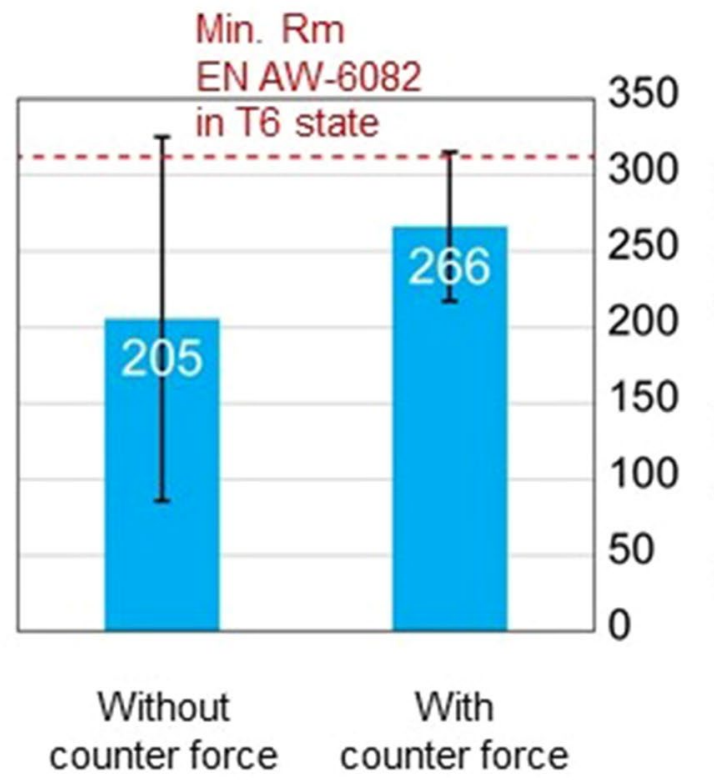

values remained below $310 \mathrm{MPa}$ - the minimum ultimate tensile strength of EN AW-6082 in the precipitation-hardened state.

\section{Improvement suggestions}

Despite the further development of the forward rod extrusion process, it was not possible to achieve the desired strength of the joining zone. For this purpose, different possibilities to readjust the process are being evaluated. One possibility is to increase the joining area between the materials. friction welding and primarily the aluminium flows. Thus, the steel geometry determines the maximum joining surface. In consideration of these facts, different geometries can be taken into account to improve the strength of the joining zone. Three possibilities are presented below.

Geometry A shows a cone on the steel side, which significantly increases the surface. Comparable geometries are already part of various research projects and even show good joining zone properties after friction welding.

Steel-sided several holes were inserted in geometry B, which are filled with aluminium during the friction welding process. In addition to the significant potential increase in 
Fig. 5 Cone geometry A and the hole geometry B

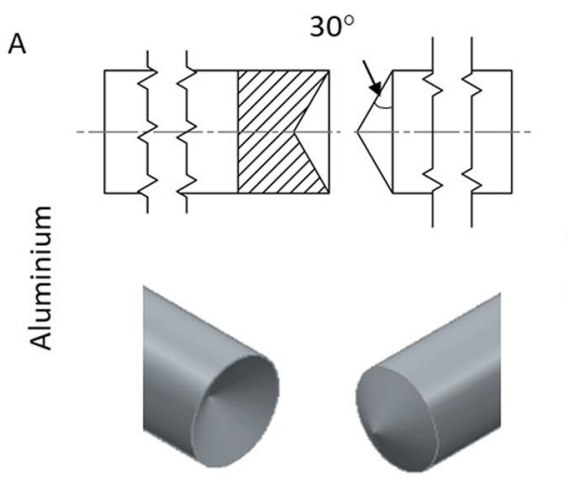

B

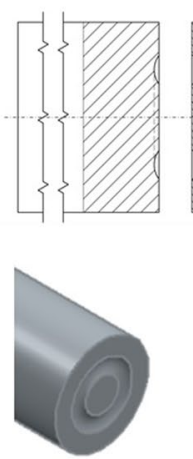

the joining surface, this geometry is particularly useful for absorbing rotational forces (Fig. 5).

Geometry $\mathrm{C}$ is designed to create a form fitting undercut. The aim is to adjust the steel geometry in a way that the aluminium is pressed into a steel die and expands. On the one hand, a stronger material connection can be generated due to the significantly larger contact surface; on the other hand, the undercut creates a form fit. This geometry can be further adjusted so that the aluminium encloses a steel-side pin during the friction welding process. This also generates a force fit connection (Fig. 6).

\subsection{Thermal process control}

Within the scope of the study, the focus is primarily on the joining zone development during the forming process. To improve this, two approaches were chosen. One of them is the blank temperature, which is adjusted by semi submerged inductive heating. Due to the hybrid design, the blank heating must be inhomogeneous. As mentioned in chapter 3 , the current heating strategy is to heat the hybrid blank exclusively on the steel side. This creates a temperature difference in the blank, which is compensated over time, as a result of heat transfer between the materials. In consequence, the steel cannot be heated to its hot forming temperature, because the aluminium would melt. Currently, the steel is formed in the range of $380-850{ }^{\circ} \mathrm{C}$, whereas the aluminium is about $380{ }^{\circ} \mathrm{C}$, in the joining zone. However, this temperature gradient is constant and ranges between 850 and $220^{\circ} \mathrm{C}$. A larger temperature difference between the materials could lead to a better formation of the joining zone, as the yield stress difference between steel and aluminium is reduced. For this purpose, immersion cooling on the aluminium side is to be integrated into the heating process. This way it is possible to dissipate unwanted heat from the aluminium into the water, to keep it from melting, and thus enables the steel to be heated to a higher temperature. The semi submerged heating process is shown in Fig. 7.

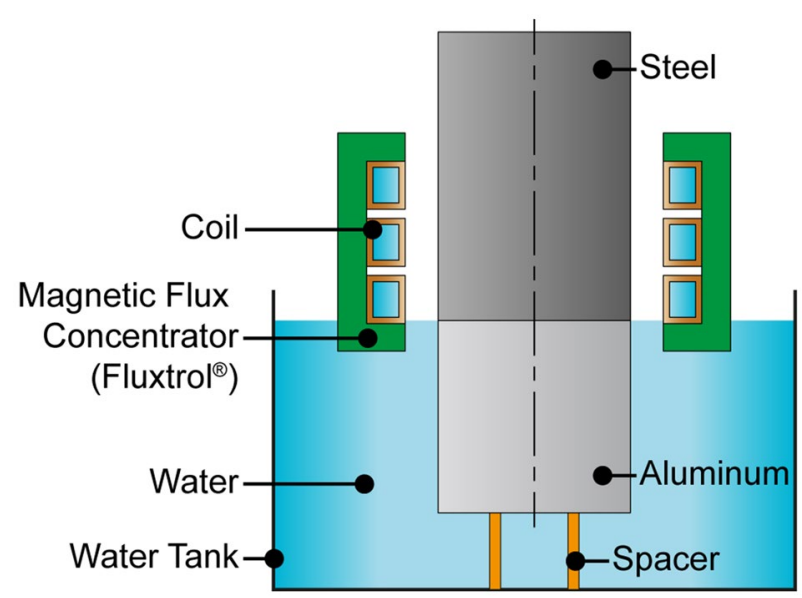

Fig. 7 Semi submerged heating
Fig. 6 Undercut geometry C

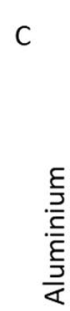

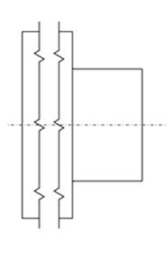

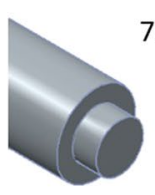

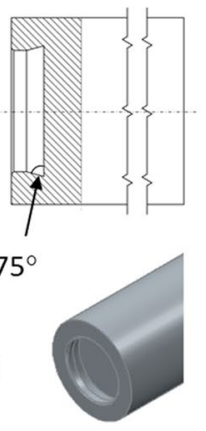

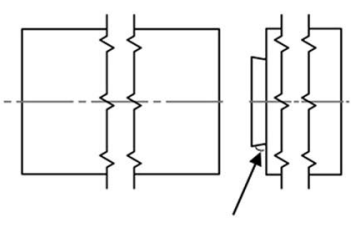

$80^{\circ}$
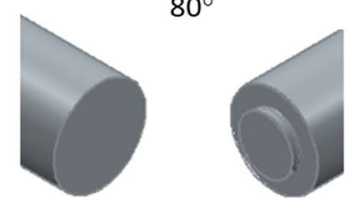


\subsection{Further extrusion processes}

The stress state within the joining zone was identified as the main influence during the forming of the hybrid blanks. This results from the differences in yield stress, but can also be adjusted by counter pressure superposition, as described in Sect. 3.2. The system developed here reaches its limits in terms of process technology, since the counter pressure mechanism counteracts the punch force and high tool loads are occurring. In order to expose the joining zone to different load profiles, other extrusion processes are used for tailored forming. For this purpose, a hollow shaft was selected as a new demonstrator component, which is to be produced by three different impact extrusion processes.

The investigation of different impact extrusion processes serves to control the load profile of the joining zone during the forming process in different ways. Cup extrusion, for example, is characterised by high degree of deformation at high surface enlargements and contact pressures. Figure 8 shows the comparison of the simulative results.
The enlargement of the surfaces at the joining zone can lead to the intermetallic phases formed during friction welding being torn open, so that newly formed surfaces come into contact. If this is done at sufficiently high contact pressures, new positive fit connections can be created or the properties of existing connections can be improved by thermomechanical treatment. The hollow shaft geometry and the impact extrusion processes are shown in Fig. 9.

\section{Summary}

Within the CRC 1153, processes are developed to optimise the joining zones of hybrid steel-aluminium semi-finished parts and to produce locally load-adapted components. The Tailored Forming approach allows the production of these components without defects. The strength of the component is presumably limited by the joining zone, which fails due to brittle material properties before the base material brakes. In order to obtain better component properties, different approaches are examined theoretically to improve the joining zone properties. Three approaches are being focused on.
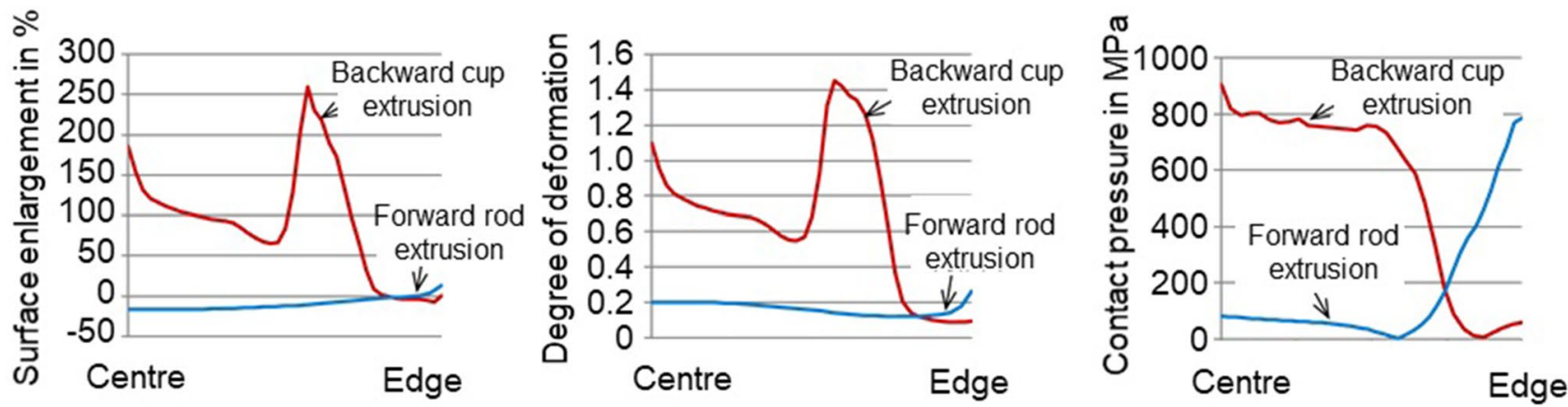

Fig. 8 Comparison of backwards cup extrusion and forward rod extrusion

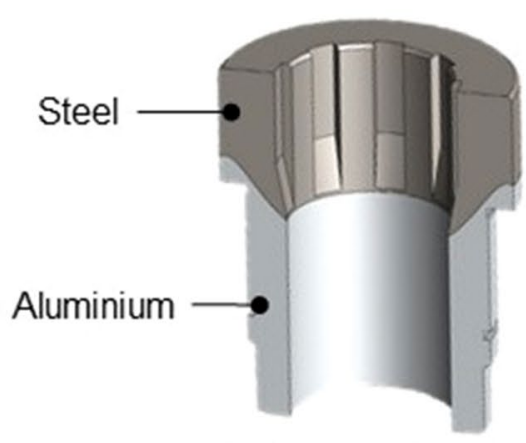

Hollow shaft demonstrator

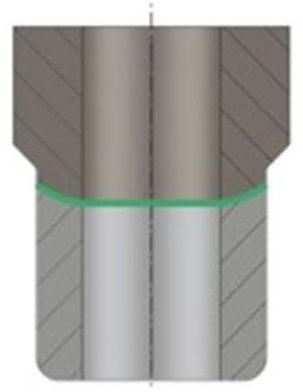
Forward tube extrusion

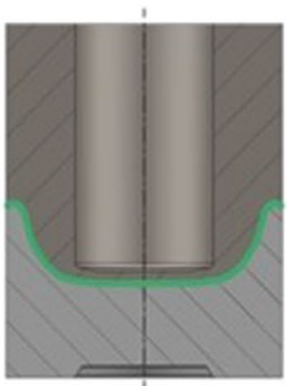

Backward can extrusion

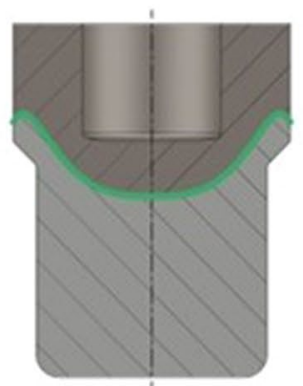

Combined forward rod and backward can extrusion

Fig. 9 Hollow shaft demonstrator and the impact extrusion processes 
On the one hand, the surface geometries of the blanks are adapted prior to friction welding in order to increase the area of the joining zone and to create a positive- and force fit between the materials in addition to the material connection.

On the other hand, there is a clear difference in yield stress between steel and aluminium at the same temperature, during the forming of the hybrid semi-finished product. Optimised heating strategies can significantly increase the temperature gradient between the materials. In this case, the aluminium side is to be cooled while the raw part is heated on the steel side.

Since the load condition within the component during forward rod extrusion damages the joining zone, new impact extrusion processes are investigated. For this purpose, a new demonstrator was developed, which can be produced by three different impact extrusion processes, backward cup extrusion, combined forward rod and backward cup extrusion and forward tube extrusion.

Acknowledgements The authors also appreciate the support of the subproject A2 with the heat treatment of the tension test specimens.

Funding Open Access funding enabled and organized by Projekt DEAL. Funded by the Deutsche Forschungsgemeinschaft (DFG, German Research Foundation)-CRC 1153, subproject B03 and T02-252662854. The authors thank the German Research Foundation (DFG) for their financial support of this project.

Open Access This article is licensed under a Creative Commons Attribution 4.0 International License, which permits use, sharing, adaptation, distribution and reproduction in any medium or format, as long as you give appropriate credit to the original author(s) and the source, provide a link to the Creative Commons licence, and indicate if changes were made. The images or other third party material in this article are included in the article's Creative Commons licence, unless indicated otherwise in a credit line to the material. If material is not included in the article's Creative Commons licence and your intended use is not permitted by statutory regulation or exceeds the permitted use, you will need to obtain permission directly from the copyright holder. To view a copy of this licence, visit http://creativecommons.org/licenses/by/4.0/.

\section{References}

1. Merklein M, Johannes M, Lechner M, Kuppert A (2014) A review on tailored blanks - Production, applications and evaluation. J Mater Process Technol 214(2):151-164

2. Zadpoor AA, Sinke J, Benedictus R (2007) Mechanics of tailor welded blanks: an overview. Key engineering materials, Trans Tech Publications 344:373-382 https://doi.org/10.4028/www. scientific.net/KEM.344.373
3. Domblesky J, Kraft F, Druecke B, Sims B (2006) Welded preforms for forging. J Mater Process Technol 171-1:141-149

4. Kittner K, Awiszus B, Lehmann T, Stockmann M, Naumann J (2009) Numerische und experimentelle Untersuchungen zur Herstellung von stranggepressten Aluminium-/Magnesium-Werkstoffverbunden und zur Festigkeit des Interface. Mater Werkst 7-40:532-539

5. Lehmann T, Stockmann M, Kittner K, Binotsch C, Awiszus B (2011) Bruchmechanische Eigenschaften von $\mathrm{Al} / \mathrm{Mg}$-Verbunden und deren Fließverhalten im Herstellungsprozess. Mater Werkst 7-42:612-623

6. Awiszus B, Neugebauer R, Kittner K, Popp M (2009) Analyse des Querfließpressens als Analogieversuch zum Strangpressen unter besonderer Berücksichtigung der Verbundbildung zwischen Aluminium und Magnesium. www.utfscience.de vol IV/2009, Verlag Meisenbach $\mathrm{GmbH}$

7. Foydl A, Kosch K-G, Jaeger A, Pfeiffer I, Tekkaya AE, Behrens B-A (2013) Co-extrusion of discontinuously steel-reinforced aluminium. In: 6th JSTP International Seminar on Precision Forging (2013), Kyoto, Japan, pp 1-4

8. Behrens B-A, Tekkaya AE, Kosch K-G, Foydl A, Kammler M, Jaeger A (2013) Manufacturing of steel-reinforced aluminum parts by co-extrusion and subsequent forging. Key Eng Mater 585:149-156

9. Wang J, Langlois L, Rafig M, Bigot R, Lu H (2014) Study of the hot forging of weld cladded work pieces using upsetting tests. J Mater Process Technol 214-2:365-379

10. Kosch K-G, Frischkorn C, Huskic A, Odening D, Pfeiffer I, Pruess T, Vahed N (2012) Effizienter Leichtbau durch belastungsangepasste und anwendungsoptimierte Multimaterial-Schmiedebauteile. www.utfscience.de vol I/2012, Verlag Meisenbach $\mathrm{GmbH}$

11. Kroner A (2012) Hybridschmieden schlägt Verbindungstechnik Leiber Group GmbH \& Co KG. http://docplayer.org/112850381Hybridschmieden-schlaegt-verbindungstechnik.html. Accessed 18 Nov 2020

12. Preuss M, Withers PJ, Baxter GJ (2006) A comparison of inertia friction welds in three nickel base superalloys. Mater Sci Eng A 437:38-45

13. Roder O, Helm D, Neft S, Albrecht J, Luetjering G (2005) Mixed inconel alloy 718 inertia welds for rotating applications-microstructures and mechanical Properties. In: TMS (The Minerals, Metals \& Materials Society): 6th International Conference on superalloys $718,625,706$ and derivatives. Warrendale, pp 649-659

14. Goldstein R, Behrens B-A, Duran D (2017) Role of thermal processing in tailored forming technology for manufacturing multimaterial components, heat treat 2017. In: Proceedings of the 29th ASM heat treating society conference, October 24-26, Columbus, Ohio

15. Behrens B-A, Bonhage M, Bohr D, Duran D (2019) Simulation assisted process development for tailored forming. Mater Sci Forum 949:101-111

Publisher's Note Springer Nature remains neutral with regard to jurisdictional claims in published maps and institutional affiliations. 